\title{
Acquisition of form-class membership by syntactic position: Paradigmatic associations to nonsense syllables'
}

\author{
Sam Glueksbers and Jack A. Cohen 2 \\ PRINCETON UNIVERSITY
}

\begin{abstract}
Abstraet
CVC trigrams were used in either noun or verb positions in sentences. The sentences were constructed to preclude specific referential meanings. The CVC trigrams were then used as stimuli in a free wordassociation task. Paradigmatic associations were obtained as a function of syntactic usage.
\end{abstract}

\section{Problem}

When nonsense syllables are used in particular syntactic positions in sentences, they are subsequently employed in new sentences in correct positions, i.e., the syllables are employed in ways permitted by their part-of-speech membership (Brown \& Berko, 1960). If the syllable occupied a noun position, it is later used correctly as a noun; if it occupied a verb position, it is used as a verb.

Johnson (1965) found that the meaning acquired by virtue of syntactic position is not limited to correct contextual usage. Semantic differential ratings (Osgood, 1952) of nonsense syllables differed as a function of prior use in subject or object positions in simple sentences.

This study examines another aspect of the meaning conferred by syntactic position. Adults generally give paradigmatic associations to word stimuli, i.e., they tend to give response words in the same form-class as the stimulus word (Ervin, 1961; Palermo, 1963). Will nonsense syllables acquire this property of words when they are used in particular syntactic positions? That is, will a nonsense syllable used in a noun or verb position elicit word responses as a noun or verb would in a word-association tásk?

\section{Method}

Fifty adults served as Ss. The sample included 45 undergraduates at Princeton University, and five older adults residing in Princeton, New Jersey. Twenty-five Ss were given a word-association task which included, among a number of English words, the two CVC trigrams selected. None of the English words was a noun or a verb. The data obtained from this control group were used as an estimate of the normative population responses to the trigrams selected.

The remaining 35 Ss were each given five sentences, typed on $3 \times 5$ in cards. After each sentence had been displayed, $S$ was instructed to rate the sentence on a Semantic Differential rating sheet. Eighteen Ss were given one of the two trigrams in the noun position in all sentences; 17 Ss were given one of the two trigrams in the verb position in all sentences. No single noun or verb could reasonably fit all sentences.

The noun sentences require both mass and count nouns, and the verb sentences require both transitive and intransitive verbs. The sentences used are shown in Table 1.

The trigram inserted into the noun and verb sentence frames was either YIK or VUM (selected from Archer's list (1960), meaningful- ness rating $=30$ ). Neither trigram was ever shown in any form other than the original, i.e., neither plural nor participle endings nor verb auxiliaries were used.

After reading and rating all five sentences, Ss were given a wordassociation task. Ss were asked to give the first word that came to mind when presented with the stimulus. The stimulus words, typed on $3 \times 5$ in cards, were the same for all Ss, except that only the trigram used in the sentences was given to the experimental groups. The Semantic Differential was employed only as a cover task, and was not scored. The responses to the trigrams were coded as nouns, verbs, or other parts of speech according to the Thorndike-Barnhart Comprehensive Desk Dictionary (Barnhart, 1951). This dictionary lists words in order of their frequency of usage. The first classification listed was always used when a word could be classified as more than one part of speech.

\section{Results}

Fifty six per cent of the responses to the trigrams given by the control Ss were nouns. When the trigrams were used in noun positions, $77.8 \%$ of the responses obtained were nouns. This compares with the weighted per cent of 76.6 noun responses to noun stimuli reported by Palermo for Grade 12 Ss.

The data obtained for verb-position trigrams are similar. Only $10 \%$ of the responses to the trigrams in the control condition were coded as verbs. When the trigrams were used in verb positions, $47.1 \%$ of the responses were verbs. The per cents of verb responses to verb stimuli reported by Palermo are 45.3 and 42.4 for transitive and intransitive verbs, respectively. These data are presented in Fig. 1.

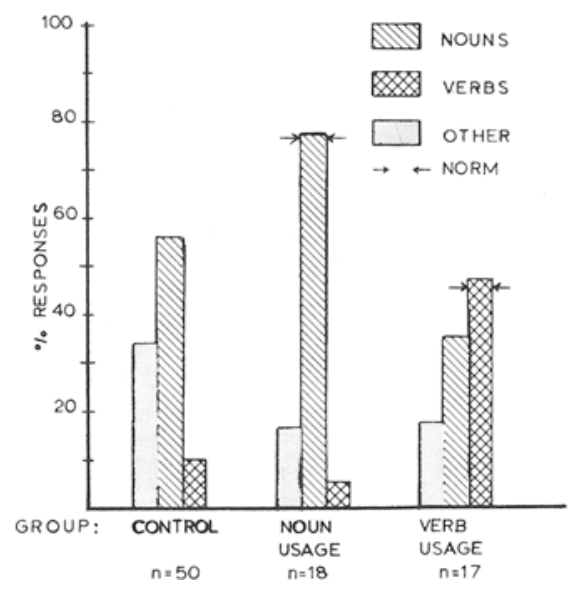

Fig. 1. Form-class of responses to trigrams as a function of trigram usage. Indicated norms are from Palermo (1963). The verb norm is for transitive verbs. 
Table 1

Noun and Verb Sentence Frames Fimnloyed

\begin{tabular}{|c|c|}
\hline Noun Frames & Verb Frames \\
\hline I bought some & Potatoes, beans and carrots never \\
\hline He climbed over the & In the midwest, people __. \\
\hline grows in temperate zones. & Next week, I intend to __ a chair. \\
\hline New Yorkers drink __ every day. & She can __ well. \\
\hline They borrowed a ___ & $\begin{array}{l}\text { It is dangerous to } \\
\text { numbered years. }\end{array}$ \\
\hline
\end{tabular}

\section{Diseussion}

The data clearly demonstrate that the trigrams did acquire a specific stimulus property by being used in particular syntactic positions. When used as nouns, they acquired a property of n o u n-n e s s, even when presented out of a sentence context. An identical effect was obtained for verb usage. However, these trigrams acquired no uniform specific referential meaning. In general, Ss could not report the meaning of the trigram used. Furthermore, even if they did notice that it was a verb or a noun, they were not aware of the literature on the paradigmatic nature of word-associations.

These findings extend those of Brown \& Berko (1960) in three ways. The first two concern the nature of the effective variable in the syntactic position effect. The third demonstrates a more general effect of syntactic position.

1. The effect of syntactic position is not dependent upon specific referential meaning.

2. The effect is not dependent upon the use of specific auxiliary words (e.g., verb auxiliaries), nor is it dependent upon form-class word endings, such as plural, tense, or participle endings.

These two findings suggest that syntactic position alone is an effective determinant of certain verbal properties.

3. The effect is not limited to syntactic usage. More generally, syntactic position invested the trigrams with a non-syntactic property of nouns and verbs-the property of functioning as noun- or verb-stimuli in a word-association task.

An additional implication suggested by these data is that paradigmatic associations are not sequential associations. Ervin (1961) attempts to account for the increase in paradigmatic responses with age by appealing to contextual generalization processes as a supplement to frequent pairings in the history of the S. For example, coffee may elicit tea because, (a) the words coffee and tea have often been experienced together, and (b) the word coffee may be substituted for the word tea in a wide variety of verbal contexts, e.g., I often drink coffee/tea.

It would seem, in view of our findings, that the latter is the more general statement. Our data can only be accounted for in terms of some substitutability notion, based upon grammatical form-class. We assume, with Chomsky (1957), that adults have linguistic categories from which verbal units may be drawn. When generating sentences, speakers select units from several categories in sequences that are determined, in part, by the grammar of the language. When, however, speakers perform in a word-association task, they do something quite different. They appear to select words from within a given category, the category being determined partly by the form-class membership of the stimulus word. The finding that a trigram with no specific referential meaning can function as a category member implies that the category itself has psychological significance separable from the elements constituting that category.

Nouns and verbs, as well as other parts of speech, are not merely formal creations of the psychologist, linguist, and grammarian. They are functional categories embedded in man's psychological structure.

\section{References}

ARCHER, E. J. A re-evaluation of the meaningfulness of all possible CVC trigrams. Psychol. Monogr., 1960, 74, No.10 (Whole No. 497)。

BARNHART, C. L. (Ed.) Thorndike-Barnhart comprehensive desk dictionary. New York: Doubleday, 1951.

BROWN, $R_{\circ}$, \& BERKO, J. Word association and the acquisition of grammar. Child Develpm., 1960, 31, 1-14.

CHOMSKY, N. Syntactic structures. The Hague: Mouton, 1957.

ERVIN, S. M. Changes with age in the verbal determinants of word-association. Amer. J. Psychol., 1961, 74, 361-372.

JOHNSON, M. G. The effects of syntactic position on meaning. Paper read at meetings of Eastern Psychological Association, 1965.

OSGOOD, C. E. The nature and measurement of meaning. Psychol. Bull., 1952, 49, 197-237.

PALERMO, D. S. Word associations and children's verbal behavior. In L. P. Lipsitt, and C. C. Spiker (Eds.) Advances in child development and behavior. Vol 1. New York: Academic Press, $1963,31-68$.

\section{Notes}

1. This research was supported in part by Public Health Service Grant MH 10742-01.

2. The authors wish to thank the following for assistance in conducting this study: J. M. Friedman, R. N. Haarlow, G. Heaton, H. B. Sweeny, W. F. Thompson, S. N. Trautwein, P. D. Waring, and G. B. Wood. 